\title{
Much more visible now are the inequalities that have always existed in our system and much clearer the need for stronger state intervention
}

\author{
Armando De Negri Filho MD PhD \\ Collaborating Researcher, UN Research Institute for Social Development \\ Executive Committee, World Social Forum on Health and Social Security, Brazil
}

\section{Caitlin Baird PhD}

Dr Armando De Negri Filho is an epidemiologist whose work has centered on development and maintenance of Brazil's universal healthcare system. Along with his training in epidemiology, Dr De Negri has a specialty in emergency medicine and a PhD involving research focused on policy, planning, economics and health systems management. In addition to his other responsibilities, he serves as an expert on the right to development for the UN Human Rights Council. He spoke with MEDICC Review from his hometown in Porto Alegre.

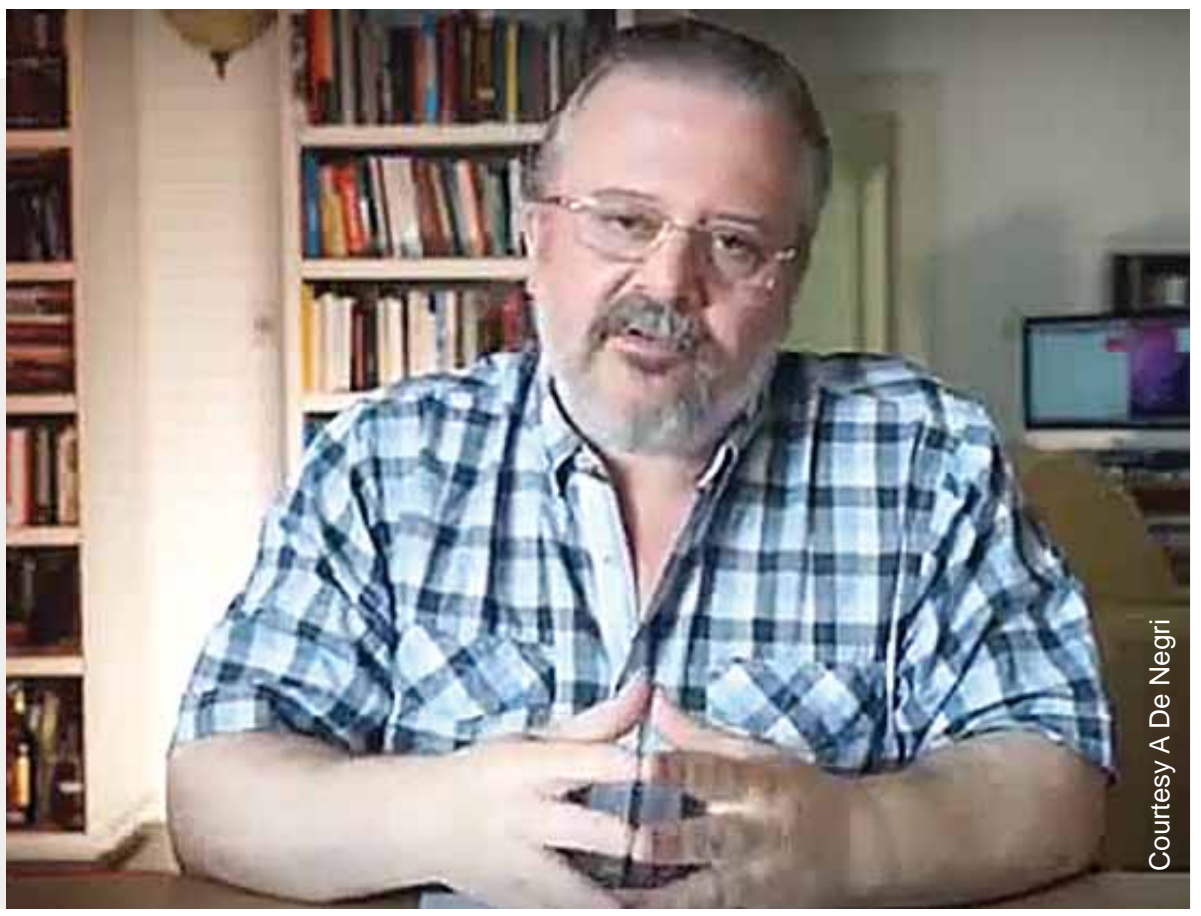

MEDICC Review: How does your current work relate to the COVID-19 pandemic?

Armando De Negri: My responsibility is mainly in a civil-society leadership team that is working on strategies to help us get through this pandemic and arrive, at the end, to a better perspective on how our system may be best served. Our activists have agreed that this is an opportunity to go beyond the limits of our national health system, which has been severely restricted during the last few years due to shortages of both financing and service development. So, we are now in a major crisis of access to health and health care-but that's not new. The pandemic is only making it much more visible.

MEDICC Review: How have your day-to-day professional responsibilities shifted since the onset of the pandemic in January?

Armando De Negri: In fact, I don't think they have shifted very much, because for many years now my place in the national health system has been in social activism and decision-making about health policies and systems. Through the coordination of various projects, I have been working to enhance our health system's capacity to meet the social needs of the population. Throughout this period, we have been very concerned with the lack of health service infrastructure necessary to make quality health care possible - this was a problem that already existed before the coronavirus pandemic.

Currently, we are trying to not only mobilize the resources necessary to face the pandemic, but also to make this crisis an opportunity to help us shift the political agenda. And I think that might be possible: much more visible now are the inequalities that have always existed in our system and much clearer the need for stronger state intervention. We can no longer continue to ignore the fact that our universal health system has been very limited in its capacity, since it has been viewed as conflicting with economic policies. Right now, when we need to protect all of society, regardless of social class, we are in a position to propose another kind of debate. So my responsibilities in the face of this pandemic become more urgent, but their academic, professional, and social nature remain the same.

MEDICC Review: So, do you believe such increased visibility for systemic inequities offers potential for positive change going forward?

Armando De Negri: I think it could. But it's not something that we would achieve organically, because of the way our society is organized. Remember that Brazilian society has been heavily influ- 
enced by its historical origins in slavery_present in our society for almost four centuries-and this history has developed a society that is, by its very nature, quite unequal. In 1988, the federal constitution established the universal right to health, but that doesn't mean that we have achieved it in every sense. Our national health system is big and everyone can access it without paying; its financing comes from taxes levied through state taxation.

However, since the adoption of our universal health system in 1988, private-sector health services have increased, accessed by about 48 million people. The universal public health system is providing services to another 170 million people, who are exclusive users of that system, with no access to private care. But the 48 million who can afford private insurance can use both private and public health services. They are doubly protected. About $45 \%$ of total health expenditures is spent on the public system, while $55 \%$ goes into private-sector health care. When you put this together, it means that some $25 \%$ of the population has access to $55 \%$ of the health resources, without being excluded from the universal health system. On the other hand, you have 170 million people that can only access services provided through the $45 \%$ of funds devoted to the public sector. The result is quite unequal in terms of the material capacities of these systems and subsystems, and of course also generates more social inequality in access to healthcare, and thus in health, within the population.

What we are observing during the pandemic is that all the resources that we have now dedicated to our health infrastructure are insufficient. Even the private sector is currently incapable of serving the needs of all 48 million people who are privately insured. So these people are putting pressure on the public system, which they can do despite the fact that they have additional, private insurance, because they are citizens. This scenario is prompting debate about the quality and strength of the public system, and is shedding light on the limitations of both healthcare systems and subsystems.

It bears repeating that what we had prior to the pandemic was insufficient. We were already observing overcrowding in emergency services, long wait times for specialized hospital care, and now we are facing a dual insufficiency-the pre-existing social debt in terms of the prevailing inequities in the health system, coupled with new needs demanded by coronavirus care. So this is a key opportunity to make the need for a stronger system much more visible.

Somebody has said "until now, the neoliberal policies were built on the idea that we could have a big boat with very few life jackets... but now that we're sinking, we're realizing that we need enough life jackets for everyone." This epiphany on why we must center, sustain and expand our national healthcare system based on the needs of society as a whole could become a strong political point to make.

\section{MEDICC Review: Looking at the structural inequalities you have described in the healthcare system, how do you see the pan- demic playing out in Brazil?}

Armando De Negri: First, we have these social class inequities that are very important, that are expressed in what you might call a planned lack of assistance. Historically, we've always struggled to have enough budget to cover social needs, and since our economic policies are very much neoliberal-oriented, we ended up with a kind of limited response to social needs-based on the "natural" assumption that the needs won't be fully addressed. This kind of behavior in the dynamics of both state and society led to systematic reductions in our structural capacities.

For example, since 1992, we have observed a continuous reduction in the number of hospital beds. This is very much linked with an imported way of thinking: the fact that most Western countries are reducing the number of beds was consistently used as an argument to support these policies. But of course, this kind of direct translation is very misleading, because in many European countries, or even the former Soviet republics, the number of hospital beds was reduced because they had a very large number in proportion to their populations, and the decrease was linked to a transformation in outpatient care plus a drastic reduction in inpatient care. And at the same time, in the case of various Western European countries, Canada and Australia, we can see that the reduction in hospital beds was too drastic, resulting in a more recent crisis in access to hospital admission.

When we compare hospital-bed numbers in Brazil with those in other universal health systems in the world, mainly in developed Western countries, we see a huge disparity. In our universal health system, we have just 1.4 hospital beds per 1000 population. The minimum that we see in these other countries with universal state access is about 3.5, 3.6, or even 3.8 per 1000 population. And even when they are nearer to 3 per 1000 than to 4 per 1000, we observe crises in access, as is the case in Ireland, the UK, Spain, Australia and elsewhere.

My activism over the past 25 years in emergency policies and services has been directed at calling for a human rights-based policy to make the number of hospital beds sufficient to meet the population's needs. Right now, without the coronavirus, we would need 500,000 more hospital beds in our country to even begin to meet the needs of the population and solve the almost total absence of care in many regions.

What's more, this very low number of hospital beds corresponds with a low number of intensive care units and also, importantly, a lack of equitable distribution among territories. We are a very big country, with problems in inequality between regions, and services are concentrated in the state capitals or in the richest regions, with a lack of specialized hospital care even within very big territories. So the historical inability to address the needs of our population is something that becomes even more concerning now, in the face of a pandemic.

Another factor to consider is that throughout the past 30 years, we have been experiencing a fast demographic transition to an older population. This means we have many more people using the health system at a much higher rate, magnifying all the problems derived from our social and economic failings. For instance, the triple burden of disease (infectious disease, chronic disease and injury) is very high, so when we combine all those dimensions-demographic, socio-economic and epidemiologic —we have an immense social need for health care that is not addressed by existing health services and budgets. So now we need to understand health services and systems as a tool to reduce or eliminate inequalities, and this realization is coming to the forefront of public consciousness.

In other words, everything we will be debating during the next weeks and months regarding coronavirus must be understood within a broader context. The pandemic is opening people's eyes to the lack of access inherent in our health system structures. We will be obliged to go far beyond the budgetary limits we have now, to review the sources of financing, and to think about health care and our health 
systems as part of the country's vital economic life. This is a case where we should spend money expecting no financial reward, because we are talking about a very important sector of the economy. Linked to this, the question of "health sovereignty" presents another grave challenge, since the pandemic has revealed that we need national industries able to produce masks, gloves and basic life support equipment for hospitals and general healthcare use. Our level of dependency on foreign industries, especially in the case of pharmaceuticals, is unacceptable, especially in a country with 212 million people. And so this is a moment to change our health-related economy and our solutions, as well.

\section{MEDICC Review: Foreseeing a deep global recession, possibly even a depression, do you have any suggestions for how to best balance immediate public health demands necessitated by the coronavirus with those involved in re-invigorating the economy?}

Armando de Negri: I have been listening to the debates in other Latin American countries, and first of all, I think we must use this opportunity to design the real breadth of the health systems and healthcare networks that we need, emphasizing their linkages and interdependencies with social services. Within any health system, there is a mix of health conditions that demand health care and many situations where social services become very important. This is the case especially with longterm patients who require protection involving social institutions, including the possibility of housing support, the need for a regular income, and so on.

So, we have to map out the health and social systems we have right now in order to prompt a new debate on the resources we need, and to understand what we must do to achieve equilibrium between the needs of the population and our responses to those needs. In this sense, using the reference of social human rights is important because it forces us to think first about the needs of the people, and not about the limits of the budget.

The second point is this: once we have this broader picture of what we have and what we need, and once we have established the cost of what we must do, then we can examine the way forward more ambitiously and begin talking about how we can generate the resources necessary to meet the population's needs. Then we can begin to talk about tax justice and the effectiveness of the regional redistribution mechanisms we currently have in place to sustain universal policies. Additionally, we need to discuss the need to change most of the structures involved in our industrial capacities, including the education system's capacity for producing professionals qualified to sustain expanded, quality health care.

In doing all this, we can re-embed the economy in social life. This is fundamental. The idea that we work for the health of the economy must be substituted by the idea that the economy must develop to sustain the well-being of the people. Over the last 30 years, the economy was reduced entirely to its financial expression, with negative social effects. What became important was generating financial results, which means that we are all working in order to make rich people richer. We forgot the fact that money, in the end, is a kind of fictitious merchandise or commodity. We need money to mobilize our societies and to drive our economies, and so fine, let's make money, let's have a financial system. But this financial system has to submit to the real "living economy," meaning it is fundamental to re-embed the economy in society.
Of course, this is a very challenging debate; we're talking about a new global economic order. But this crisis is a global crisis. We cannot simply say, well, okay, now the plague is over, and we can revert to our old models. I think that won't be possible. And if we try to return to the way things were before the pandemic, I anticipate we will be facing a good deal of social conflict. Thus, it's a very important moment in history and an extremely important opportunity for mankind to change the way we have been doing things for the last several decades. As Brazilian civil society, we are very interested in social health and social security and quite motivated to contribute to this debate in different regions and countries in the hope of realizing the right to health.

I have been selected as an expert on the right to development by the UN Human Rights Council. We begin work in May. Precisely one of the opportunities the Council has now is to formulate a treaty proposal on the right to development. In the context of the current crisis, this right is fundamental, particularly as it expresses the concept that wealth that is collectively produced needs to be collectively used. This is an emerging debate within political economy, the idea that we all need to be much more critical in regard to how we produce, distribute and redistribute society's wealth.

Social protection systems in health are very important within this framework, as they are one of the best ways to redistribute riches, that is by creating universal education and health systems, and eliminating the commoditization of social protections. This is the hope we have-it's a political hope to change the nature of the debates over many decades now, to break the hegemony of neoliberal policies, and to institute new perspectives for humankind.

MEDICC Review: Given that the majority of MEDICC Review's readership are physicians and public health professionals, is there anything else that you would like our readers to know or to be thinking about as we move forward globally through this unique point in our collective history?

Armando De Negri: Well, I think it's often the case that health professionals are not very conscious about the complex nature of the health systems in which they work. Our medical pedagogy is usually very removed from a deeper understanding of these complexities, as well as the importance we have, as professionals, in the maintenance or the transformation of these systems. So it is essential in this context to reinforce an ethical approach based on human rights and think about what this means for health professionals. When we consider how health professionals are recognized and evaluated in society, I believe we need to stress the importance and the public value of the health professions in a way that could help to reinforce both the public systems and the dignity of work in health and health care.

Now is the time to think about that. Otherwise, especially among medical people, we can often be dominated by ideas of prestige and money, while lacking awareness about the public importance of our work. In the context of the pandemic, discussions about the ethical obligations of the health professions are very important, as well as continuing discussions of working conditions and salaries. This is a moment to build a new understanding of what health professionals are and what they should be, including our fundamental duty to enhance and develop universal systems that can take care of everyone. $-1 /$ - 